\title{
RAPID RELIEF OF TREATMENT RESISTANT DEPRESSION BY FACILITATED KETAMINE INFUSION: A PRELIMINARY REPORT
}

\author{
Steven R. Devore Best ${ }^{*}$ \\ The Neuroscience Center, LLC, Deerfield, IL USA
}

\begin{abstract}
By combining transcranial magnetic stimulation (TMS) with intravenous ketamine therapy, we sought to increase the therapeutic value of TMS and, at the same time, to improve the efficacy of intravenous ketamine therapy among depressed patients previously classified as non-responders. In this preliminary report, we provide evidence for a new and much more reliable method of treating patients with treatment resistant depression. Twenty-eight patients with various degrees of treatment unresponsive depression were treated with a combination of TMS and ketamine infusion. Of these patients, twenty received pretreatment for 3 days to 2 weeks involving intensive (thrice daily) rTMS treatment administered 6 or 7 days/week or priming TMS treatment immediately prior to the combination TMSketamine infusion combination therapy. Eight patients received neither pretreatment nor priming. All of the 28 patients who did fully participate in the first month of treatment experienced relief of psychiatric symptoms, and showed significant psychosocial recovery. In contrast to previous studies examining ketamine or rTMS individually, the positive outcomes presented here suggest a synergistic effect of the combination therapy of TMS and ketamine infusion.
\end{abstract}

Key words: Treatment-resistant depression; Transcranial magnetic stimulation (TMS); Transcranial Electrical Stimulation (tES); NMDA-R antagonist; Ketamine infusion; Neuromodulation; Synergistic effect; Remission

\section{INTRODUCTION}

\subsection{Scope of the Problem}

Neuropsychiatric disorders strike millions of people worldwide. Many patients do not respond to traditional treatments for these disorders. This is particularly true of major depression, which is associated with substantial economic burden. For instance, results of the Sequenced Treatment Alternatives to Relieve Depression (STAR*D) study predict that only a third of the 20 million Americans diagnosed with a major mood disorder will achieve full remission, with a significant patient population remaining refractory to pharmacologic interventions even after well targeted attempts at treatment with trials of a variety of

${ }^{*}$ Correspondence to: Steven R. Devore Best, e-mail: srdbest@neuroscience.md

Received November 11, 2013; accepted June 28, 2014; Act Nerv Super 56(1-2), 28-36; ISSN-1802-9698 Author Note: The author has filed patent application(s) on the subject matter of this article. ClinicalTrials.gov Identifier: NCT01816958 
antidepressant medications (National Institute of Mental Health; Warden, Rush, Trivedi, Fava, \& Wisniewski, 2007). Similarly, a third of the United States population suffers from depression-related chronic, non-remitting emotional pain. By some estimates $40 \%$ of the population experiences chronic pain when somatic and emotional sequelae are combined (Institute of Medicine of the National Academies of Science, Report Brief, June 2011).

\subsection{Options for treatment resistant depression}

The application of novel brain stimulation techniques to treat depression, other neuropsychiatric disorders, and "somatic pain" is a new and rapidly growing field. Among these techniques, transcranial low voltage electrical stimulation (tES) and transcranial magnetic stimulation (TMS) are emerging as promising approaches because of their relative ease of use, safety, and neurobiological effects (Gersner, Kravetz, Feil, Pell, \& Zangen, 2011; Muller, Toschi, Kresse, Post, \& Keck, 2000; Walter, 2011). TMS appears to be more potent than transcranial low voltage electrical stimulation (Holtzheimer \& Mayberg, 2012; Loo et al., 2012; Walter, 2011). Unfortunately, TMS is limited by the need for a substantial period of rigorously scheduled treatments (daily for 4-6 weeks), which can create a significant human burden in terms of delayed onset of relief, time, and money. These limitations often result in poor patient compliance (O'Reardon et al., 2007). Even when we accelerate the process by treating more times per day, the outcome of rTMS treatments is less than satisfying (Anderson et al., 2006; Holtzheimer et al., 2010). Although some of the inconvenience is mitigated by this acceleration, the response and remission rates achieved are about the same (Anderson et al., 2006; Holtzheimer et al., 2010).

The use of conventionally applied rTMS has been variously reported to produce a significant response in $41 \%$ of patients (IDS-SR outcome) and remission in $24 \%-29 \%$ of patients (IDS-SR outcome) (Allan, Herrmann, \& Ebmeier, 2011; Carpenter et al., 2012). The same application of rTMS was reportedly somewhat less effective in treating severe depression (Cusin \& Dougherty, 2012). Treatment resistance is an important factor in predicting the likelihood of response to rTMS-the more resistant a patients' illness has been to well applied medication protocols, the less likely that rTMS will be helpful (Lisanby et al., 2008). Because of this finding, conventional rTMS has been positioned as a treatment for people who have not responded to one adequate trial of medication. In the form in which it is typically available in the USA, rTMS is not currently seen as a treatment for people with multiple treatment failures. Nevertheless, rTMS has been found to have beneficial effects on overall brain function in experimental studies both in individuals who are ill as well as in those who are "well" (Chang et al., 2010; Gersner et al., 2011; Lou, Luber, Stanford, \& Lisanby, 2010; Muller et al., 2000; Pascual-Leone, Walsh, \& Rothwell, 2000; Rossi et al., 2001; Snyder et al., 2003; Young, Camprodon, Hauser, Pascual-Leone, \& Saxe, 2010).

A variant of TMS called "deep TMS" was recently approved by the U.S. Food and Drug Administration because it was apparently capable of causing a significant response in $36.7 \%$ of patients in treatment-resistant depression, compared with a response rate of $20.5 \%$ in the control group, and causing remission in about $30.4 \%$ of patients with treatment-resistant depression compared with a remission rate of $14.5 \%$ in the control group (source was a press release posting by the manufacturer in April 2012 (Globe Newswire, 2012), see also Bersani et al. (2013). Thus, antidepressant medications and commonly used neuromodulation protocols appear to be about as effective as the so-called placebo response of approximately $40 \%$ (Fava, Evins, \& Dorer, 2003; Rutherford \& Roose, 2013; Rutherford, Rose, Sneed, \& Roose, 2013).

In addition to techniques such as external neuromodulation, many pharmaceutical agents are currently available to treat neurological disorders in outpatient settings. However, these pharmaceutical agents are limited in their effectiveness and also by their significant side effects. For example, many of these medications are known to cause light-headedness, depression, insomnia, weight change, sexual dysfunction, cognitive dysfunction, weakness, fatigue, tinnitus, hallucinations, and other side effects that severely limit their use in the clinic. 
Recently, interest has grown concerning the use of novel glutamatergic drugs (Lapidus, Soleimani, \& Murrough, 2013; Pankevich, Davis, \& Altevogt, 2011) including the NMDA receptor antagonists to treat neuropsychiatric disorders (Preskorn, 2012). NMDA inhibitors are a class of psychopharmacologic agents that work to antagonize or partially inhibit the action of the N-methyl-D-aspartatereceptor (NMDA-R). The state of anesthesia they can induce is referred to as dissociative anesthesia.

One particular NMDA inhibitor, ketamine, has been shown to be effective in treating depression in patients with bipolar disorder who have not responded to antidepressant medications (Preskorn, 2012). In patients with major depressive disorder and bipolar depression, ketamine can produce a rapid antidepressant effect, acting within 2 hours as opposed to the several weeks often needed to achieve a response with typical antidepressants. When used alone, ketamine appears to provide 4-7 days of relief from suicidality; however, ketamine does not appear to provide lasting relief from suicidality or depression (Murrough et al., 2013; Preskorn, 2012). Similarly, ketamine is effective for pain relief when administered in highly complicated infusion programs to patients with severe pain syndromes like CRPS/RSD (Complex Regional Pain Syndrome/Reflex Sympathetic Dystrophy); however, it unfortunately has no particular utility for effecting psychosocial rehabilitation (Sigtermans et al., 2009).

Hence, the primary goal of the present study is to identify a therapy that will provide a greater likelihood of lasting successful results than has been achieved with ketamine or TMS along, while hopefully reducing the undesirable adverse effects of the conventional pharmacopoeia (Cazzoli et al., 2012; Gersner et al., 2011; Wang et al., 2011).

\subsection{Scientific Rationale}

In the N-back test, patients are presented with a consecutive series of stimuli and asked to respond when a given stimulus was presented $\mathrm{N}$ steps previously, where $\mathrm{N}$ is a number of steps, usually 1-3. The N-back test places a heavy cognitive load on the working memory system, which is involved in depression (Salvadore et al., 2010). Salvadore and colleagues showed that patients who exhibited the least activation of the perigenual anterior cingulate cortex (pgACC) during the N-back task also showed the most improvement in depression symptoms after ketamine administration. In additon, functional connectivity between the pgACC and the left amygdala was negatively associated with depression symptom reduction, suggesting that syncronization of this circuit may play a role in maintaining depression (Salvadore et al., 2010). We hypothesized that TMS temporarily interferes with the pathologic synchronization of anterior cingulate gyrus function and that this interference could make combined ketamine/TMS treatment a very useful therapy in the everyday toolbox at the clinic (Allen, Pasley, Duong, \& Freeman, 2007; Briggs \& Usrey, 2008; Esser, Hill, \& Tononi, 2005; Fuggetta \& Noh, 2013; Johnson, Hamidi, \& Postle, 2010; Massimini, Ferrarelli, Sarasso, \& Tononi, 2012; Sherman, 2007; Thut et al., 2011).

\section{METHODS}

All patients (15 male, 13 female) gave informed consent (see Table 1). The combination therapy was discussed with family members, a few times with the family Pastor, and any psychotherapists treating the patients. Relevant data were gleaned retrospectively from patient medical records, and IRB approval was obtained from an independent review board. The combination therapy was provided concurrently by the author, a neuropsychiatrist with 14 years of experience administering TMS, and an anesthesiologist or certified registered nurse anesthetist. This combination therapy was offered to established patients who had shown an inadequate response to previous treatments at the clinic (including rTMS, vagus nerve stimulation [VNS], transcranial Electrical Stimulation [tES]), and off-site treatment in other 
clinics ([ECT], hyperbaric oxygen treatments, medications including more traditional ketamine infusions, and alternative treatments such as homeopathy). Some of the patients had been fully treatment-resistant to their previous treatments, while some had only been able to maintain stability from active illness and fragile remission at the expense of regular clinic visits. Most patients were already aware of electromagnetic brain stimulation, and some had also experienced ketamine treatment in other clinical settings. The patients were informed of the new combination therapy and how it would make their everyday schedule lighter by adding ketamine infusions to the cocktail of treatments they were already receiving. Some patients discussed the idea with other healthcare providers and some reviewed medical literature, while others observed the treatment of other patients from a distance in order to develop an understanding of whether they wanted to be involved in the new combination therapy.

Patients were treated with TMS in combination with the NMDA Receptor inhibitor ketamine. The dosage for infused ketamine ranged from about $20 \mathrm{mg}$ at the beginning, to about $300 \mathrm{mg}$, delivered in a standard commercial formulation within the time-course of the TMS treatment--dosage was individually tailored for each patient in relation to response (see Table 2). The duration of the combination treatment ranged from approximately 20 minutes to about 120 minutes at an appropriate dosage level. Ketamine was infused within the course of a TMS treatment lasting approximately 60 minutes. The electromagnetic stimulation of the combination therapy was applied shortly before the ketamine was administered and was then continued during the infusion and for 5 minutes after the infusion was completed. In these patients with treatment-resistant depression, the TMS head-coil was directed toward the medial prefrontal area that overlays the anterior cingulate region. The frequency of the dose was generally $1 \mathrm{~Hz}$ and stimulation was continuous during the combination treatment.

Table 1. Patient demographics

\begin{tabular}{|c|c|c|c|c|}
\hline Patient ID & Age & Gender & Primary Dx & Secondary Dx \\
\hline D23 & 44 & Female & Unipolar Depression & PTSD, Fibromyalgia \\
\hline D26 & 23 & Male & Bipolar Depression & Substance Abuse \\
\hline D3 & 23 & Female & Unipolar Depression & ADD \\
\hline D6 & 27 & Female & Bipolar Depression & None \\
\hline E11 & 30 & Male & Bipolar Depression & Tic Disorder \\
\hline F20 & 60 & Male & Unipolar Depression & ADD \\
\hline F8 & 71 & Female & Unipolar Depression & Anxiety \\
\hline $\mathrm{J} 2$ & 31 & Female & Bipolar Depression & None \\
\hline M10 & 26 & Female & Unipolar Depression & $\begin{array}{l}\text { Complex Regional Pain } \\
\text { Syndrome }\end{array}$ \\
\hline O12 & 35 & Female & Unipolar Depression & Epilepsy \\
\hline O19 & 35 & Male & Unipolar Depression & Substance Abuse \\
\hline $\mathrm{O} 25$ & 35 & Male & Unipolar Depression & Panic Disorder \\
\hline O33 & 45 & Male & Bipolar Depression & Substance Abuse \\
\hline P13 & 70 & Male & Bipolar Depression & Chronic Pain \\
\hline P14 & 65 & Male & Unipolar Depression & ADD, Alcohol Abuse \\
\hline P30 & 65 & Female & Unipolar Depression & Fibromyalgia, Back Pain \\
\hline P7 & 35 & Female & Unipolar Depression & Multiple Head Injuries \\
\hline Q34 & 42 & Male & Unipolar Depression & $\begin{array}{l}\text { ADHD, Head Injuries, Back } \\
\text { Pain, Substance Abuse }\end{array}$ \\
\hline S9 & 45 & Male & Bipolar Depression & None \\
\hline $\mathrm{T} 17$ & 30 & Female & Unipolar Depression & PTSD, Substance Abuse \\
\hline $\mathrm{T} 32$ & 21 & Male & Unipolar Depression & OCD, Substance Abuse \\
\hline U1 & 30 & Female & Unipolar Depression & $\begin{array}{l}\text { Generalized Anxiety } \\
\text { Disorder }\end{array}$ \\
\hline U36 & 50 & Male & Unipolar Depression & Panic Disoder \\
\hline V15 & 40 & Male & Bipolar Depression & \\
\hline V29 & 30 & Male & Bipolar Depression & Past Substance Abuse \\
\hline Y24 & 66 & Male & Unipolar Depression & \\
\hline Y27 & 25 & Female & Bipolar Depression & $\mathrm{ADD}$ \\
\hline Y4 & 50 & Female & Unipolar Depression & ADD \\
\hline
\end{tabular}


Table 2. Treatment and outcome data.

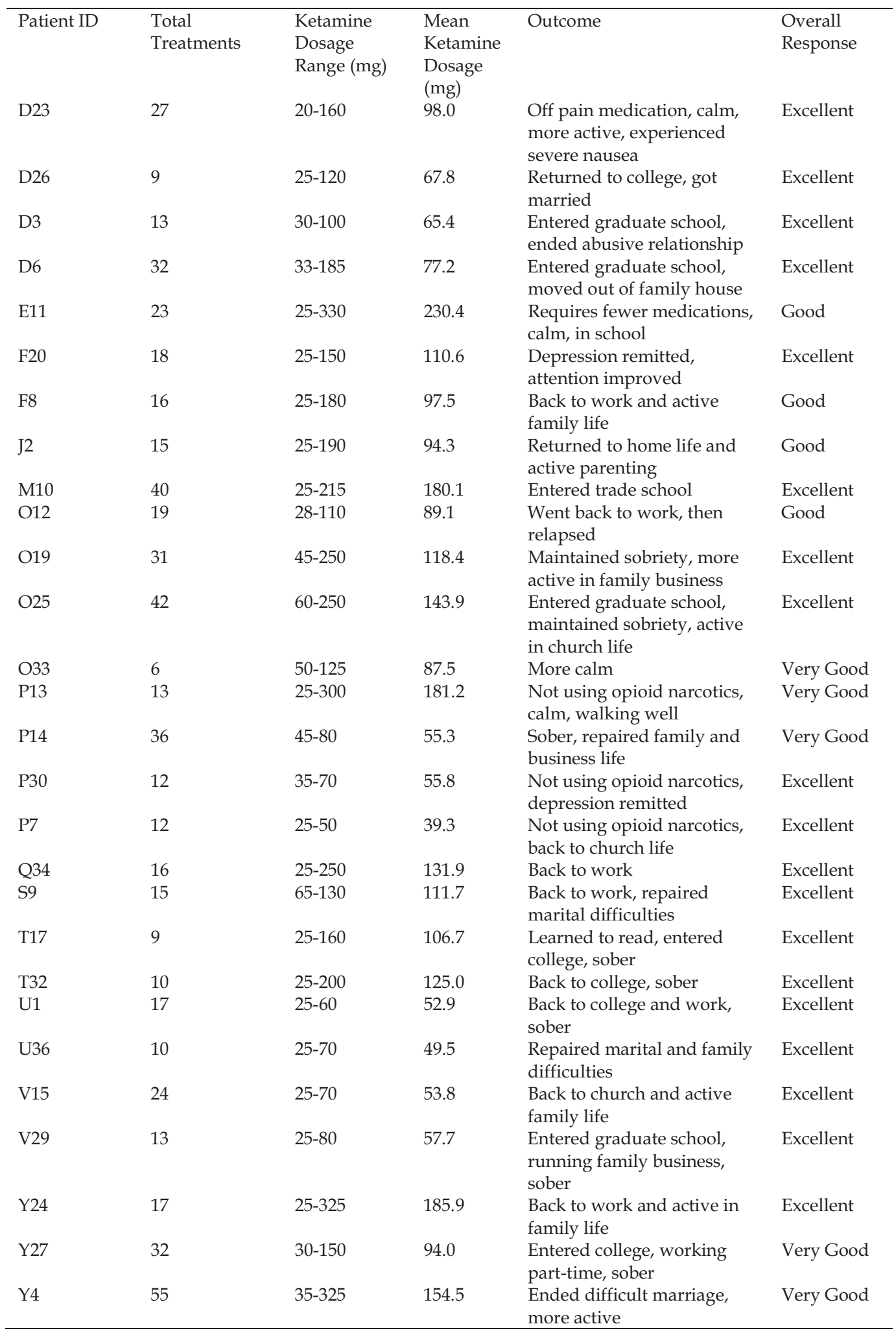




\section{RESULTS}

Twenty-eight patients with depressive syndromes and various degrees of unresponsiveness to standard therapies were selected for the combination treatment. Our description of outcome is not derived from statistical analysis of standardized measurement tools. Our clinical style is one of continuously engaging the patient and their family or friends, as well as very frequent collaboration with other providers. So when we describe an outcome as partial or nearly-full remission, we are indicating that the patient has achieved both significant relief from discrete symptoms, and commenting on our perception of the objective signs noticed during the lengthy clinic contacts, and also from the vantage of psychosocial outcome. Significant positive outcomes were associated with the combination therapy of TMS plus ketamine when the combination was delivered on a weekly or bi-weekly basis. Most patients were able to slowly taper the treatment frequency and then stop treatment after having met their individual objectives for well-being; some returned to the combination treatment after a number of weeks or even months in the manner of ongoing widely spaced maintenance treatments (Table 1). Seven patients left treatment for reasons not related to the efficacy or tolerability of the combintation treatment (one diagnosed with a fatal illness, two moved from area, one disliked the anesthetic procedure, and one each dropped out for finances, schedule issues, or desire to stay on opioids). Of the 28 patients who fully participated in the first month of this treatment, each responded in clinically significant ways, and had measurable psychosocial recovery that met the definition for partial remission or nearly full-remission (Table 2).

Our clinical work is guided by the idea that both symptom relief and stable psychosocial recovery should be considered as equally valid components in measuring outcome. We did not apply study measures such as rating scales because we were not conducting a study. Although the patients were fully aware that this was an un-tried approach, it was not created as a research project and it was not managed in that way at any time.

Obvious improvements in symptoms and psychosocial function were observed after about five treatments, which typically occurred over 3-5 weeks. However, positive outcomes were also achieved when treatments were administered at longer or shorter intervals---intervals were sometimes sporadic due to everyday schedule conflicts. Patients with depression showed the fastest response to treatment while several additional treatment sessions were usually needed before there were strong indications of recovery in patients with co-morbid chronic pain, especially when the pain was accompanied by severe depression and/or addiction. The positive response observed with this combination treatment, which tended to be robust, was obtained with negligible adverse effects; positive outcomes included: a return to work, rehabilitating a failing business, returning to college, getting married, reconciling a failing relationship, dependable recovery from substance abuse, and dramatic reductions in destructive doses of prescribed opioid narcotics. Each of the 28 patients who achieved positive results after receiving the combination therapy had previously failed all other treatments for their conditions.

\section{DISCUSSION}

Based on the findings from this open-label treatment, the combination therapy described here appeared to produce better outcomes while using lower doses of ketamine in combination with TMS. Because less ketamine was necessary, the treatment resulted in fewer side effects, and no adverse outcomes occurred. In addition, the need for less frequent TMS resulted in better patient adherence, which itself contributes to more positive outcomes. In fact, patients who initially experienced relief from the combination treatment tended to be motivated to receive additional treatments that provided lasting benefit. 


\subsection{Limitations}

This open-label treatment was offered to only the very most ill patients in my clinic during the months in question. These patients were chronically impaired and had not achieved satisfactory relief in spite of good treatment by other clinics and also while under my care. The patients tend to be unusual in that they have been referred in order to obtain neurophysiologic measures of brain health and illness. So, our patients may tend to have a greater level of hopefulness.

\subsection{Future Research Directions}

In addition to using standardized methods to assess patient symptomatology, future research should evaluate EEG on a serial basis as a direct measure of normalization of thalamocortical circuit reactivity. Such an aim would be highly compatible with the Research Domain Criteria initiative (rDOC) launched by the NIMH. The rDOC seeks to identify neurobiological dimensions that underlie and cut across mental disorders so that individuals at risk for developing a particular disorder can be identified and treated prior to its emergence. Additionally a well defined control group with at least a single blinded study design would be beneficial. In the best of worlds, we would examine specific genetic, metabolic, neurophysiologic, and personality measures as we worked to discern the reasons for why such a blunt procedure works uniformly for so many different types of suffering (Liu, Franaszczuk, Crone, Jouny, \& Lenz, 2011) and how we can use this opportunity to interrupt a disease process and re-direct nervous function to a robust well-state. The factors to consider for evaluating, intervening, and treating are stunningly complex.

\section{REFERENCES}

Allan, C.L., Herrmann, L.L., \& Ebmeier, K.P. (2011). Transcranial magnetic stimulation in the management of mood disorders. Neuropsychobiology, 64, 163-169.

Allen, E.A., Pasley, B.N., Duong, T., \& Freeman, R.D. (2007). Transcranial magnetic stimulation elicits coupled neural and hemodynamic consequences. Science, 317, 1918-1921.

Anderson, B., Mishory, A., Nahas, Z., Borckardt, J.J., Yamanaka, K., Rastogi, K., \& George, M.S. (2006). Tolerability and safety of high daily dosese of repetitive transcranial magnetic stimulation in healthy young men. Journal of ECT, 22, 49-53.

Bersani, F.S., Minichino, A., Enticott, P.G., Mazzarini, L., Kahn, N., Antonacci, G., Raccah, R.N., Salviati, M., Delle Chiaie, R., Bersani, G., Fitzgerald, P.B., Biondi, M. (2013). Deep transcranial magnetic stimulation as a treatment for psychiatric disorders: A comprehensive review. European Psychiatry, 28, 30-39.

Briggs, F., \& Usrey, W.M. (2008). Emerging views of corticothalamic function. Current Opinion in Neurobiology, 18, 403-407.

Carpenter, L.L., Janicak, P.G., Aaronson, S.T., Boyadjis, T., Brock, D.G., Cook, I.A., Dunner, D.L., Lanocha, K., Solvason, H.B., Demitrack, M.A. (2012). Transcranial magnetic stimulation (TMS) for major depression: A multisite, naturalistic, observational study of acute treatment outcomes in clinical practice. Depression and Anxiety, 29, 587-596.

Cazzoli, D., Muri, R.M., Schumacher, R., von Arx, S., Chaves, S., Gutbrod, K., Bohlhalter, S., Bauer, D., Vanbellingen, T., Bertschi, M., Kipfer, S., Rosenthal, C.R., Kennard, C., Bassetti, C.L., Nyffeler, T. (2012). Theta burst stimulation reduces disability during the activities of daily living in spatial neglect. Brain, 135, 3426-3439.

Chang, W.H., Kim, Y-H, Bang, O.Y., Kim, S.T., Park, Y.H., \& Lee, P.K.W. (2010). Long-term effects of rTMS on motor recovery in patients after subacute stroke. Journal of Rehabilitation Medicine, 42, 758-764.

Cusin, C., \& Dougherty, D.D. (2012). Somatic therapies for treatment-resistant depression: ECT, TMS, VNS, DBS. Biology of Mood E Anxiety Disorders, 14, 1-9.

Esser, S.K., Hill, S.L., \& Tononi, G. (2005). Modeling the effects of transcranial magnetic stimulation on cortical circuits. Journal of Neurophysiology, 94, 622-639.

Fava, M., Evins, A.E., \& Dorer, D.J. (2003). The problem of the placebo response in clinical trials for 
psychiatric disorders: Culprits, possible remedies, and a novel study design approach. Psychotherapy and Psychosomatics, 72, 115-127.

Fuggetta, G., \& Noh, N.A. (2013). A neurophysiological insight into the potential link between transcranial magnetic stimulation, thalamocortical dysrhythmia, and neuropsychiatric disorders. Experimental Neurology, 245, 87-95.

Gersner, R., Kravetz, E., Feil, J., Pell, G., \& Zangen, A. (2011). Long-term effects of repetitive transcranial magnetic stimulation on markers for neuroplasticity: Differential outcomes in anesthetized and awake animals. Journal of Neuroscience, 31, 7251-7526.

GlobeNewswire. (2012). Brainsway reports positive pivotal multicenter major depression trial results. Retrieved June 25, 2014

Holtzheimer, P.E., \& Mayberg, H.S. (2012). Neuromodulation for treatment-resistant depression. F100 Medicine Reports, 4, 1-10.

Holtzheimer, P.E., McDonald, W.M., Mufti, M., Kelley, M.E., Quinn, S., Corso, G., \& Epstein, C.M. (2010). Accelerated repetitive transcranial magnetic stimulation for treatment-resistant depression. Depression and Anxiety, 27, 960-963.

Institute of Medicine of the National Academies of Science (2011). Relieving pain in America: A blueprint for transforming prevention, care, education, and research. www.iom.edu/relievingpain

Johnson, J.S., Hamidi, M., \& Postle, B.R. (2010). Using EEG to explore how rTMS produces its effects on behavior. Brain Topography, 22, 281-293.

Lapidus, K.A.B., Soleimani, L., \& Murrough, J.W. (2013). Novel glutamatergic drugs for the treatments of mood disorders. Neuropsychiatric Disease and Treatment, 9, 1101-1112.

Lisanby, S.H., Husain, M.M., Rosenquist, P.B., Maixner, D., Gutierrez, R., Krystal, A., Gilmer, W., Marangell, L.B., Aaronson, S., Daskalakis, Z.J., Canterbury, R., Richelson, E., Sackeim, H.A., George, M.S. (2008). Daily left prefrontal repetitive transcranial magnetic stimulation in the acute treatment of major depression: Clinical predictors of outcome in a multisite, randomized controlled clinical trial. Neuropsychopharmacology, 34, 522-534.

Liu, C.C., Franaszczuk, P., Crone, N.E., Jouny, C., \& Lenz, F.A. (2011). Studies of properties of "pain networks" as predictors of targets of stimulation for treatment of pain. Frontiers in Integrative Neuroscience, 5, 1-7.

Loo, C.K., Alonzo, A., Martin, D., Mitchell, P.B., Galvez, V., \& Perminder, S. (2012). Transcranial direct current stimulation for depression: 3-week, randomised, sham-controlled trial. British Journal of Psychiatry, 200, 52-59.

Lou, H.C., Luber, B., Stanford, A., \& Lisanby, S.H. (2010). Self-specific processing in the default network: A single-pulse TMS study. Experimental Brain Research, 207, 27-38.

Massimini, M., Ferrarelli, F., Sarasso, S., \& Tononi, G. (2012). Cortical mechanisms of loss of consciousness: Insight from TMS/EEG studies. Archives Italiennes de Biologie, 150, 44-55.

Muller, M.B., Toschi, N., Kresse, A.E., Post, A., \& Keck, M.E. (2000). Long-term repetitive transcranial magnetic stimulation increases the expression of brain-derived neurotrophic factor and cholecystokinin mRNA, but not neuropeptide tyrosine mRNA in specific areas of rat brains. Neuropsychopharmacology, 23, 205-215.

Murrough, J.W., Perez, A.M., Pillemer, S., Stern, J., Parides, M.K., aan het Rot, M., Collins, K.A., Mathew, S.J., Charney, D.S., Iosifescus, D.V. (2013). Rapid and longer-term antidepressant effects of repeated ketamine infusions in treatment-resistant major depression. Biological Psychiatry, 74, 250-256.

NationalInstituteofMentalHealth. The numbers count: Mental disorders in America. Retrieved June 25, 2014

O'Reardon, J.P., Solvason, H.B., Janicak, P.G., Sampson, S., Isenberg, K.E., Nahas, Z., McDonald, W.M., Avery, D., Fitzgerald, P.B., Loo, C., Demitrack, M.A., George, M.S., Sackeim, H.A. (2007). Efficacy and safety of transcranial magnetic stimulation in the acute treatment of major depression: A multisite randomized controlled trial. Biological Psychiatry, 62, 1208-1216.

Pankevich, D.E., Davis, M., \& Altevogt, B.M. (2011). Glutamate-related biomarkers in drug development for disorders of the nervous system: Workshop summary. Washington, DC.

Pascual-Leone, A., Walsh, V., \& Rothwell, J. (2000). Transcranial magnetic stimulation in cognitive neuroscience -- virtual lesion, chronometry, and functional connectivity. Current Opinion in Neurobiology, 10, 232-237.

Preskorn, S.H. (2012). Ketamine: The hopes and the hurdles. Biological Psychiatry, 77, 522-523.

Rossi, S., Cappa, S.F., Babiloni, C., Pasqualetti, P., Miniussi, C., Carducci, F., Babiloni, F., Rossini, P.M. (2001). Prefrontal cortex in long-term memory: an "interference" approach using magnetic stimulation. Nature Neuroscience, 4, 948-952.

Rutherford, B.R., \& Roose, S.P. (2013). A model of placebo response in antidepressant clinical trials. American Journal of Psychiatry, 170, 723-733. 
Rutherford, B.R., Rose, S., Sneed, J., \& Roose, S.P. (2013). Study design affects participant expectations: A survey. Journal of Clinical Psychopharmacology, 29, 1-6.

Salvadore, G., Cornwell, B.R., Sambataro, F., Latov, D., Colon-Rosario, V., Carver, F., Holroyd, T., DiazGranados, N., Machado-Vieira, R., Grillon, C., Drevets, W.C., Zarate, C.A. (2010). Anterior cingulate desynchronization and functional connectivity with amygdala during a working memory task predict rapid antidepressant response to ketamine. Neuropsychopharmacology, 25, 1415-1422.

Sherman, S.M. (2007). Thalamocortical loops and information processing Encyclopedia of pain (pp. 2427-2431).

Sigtermans, M.J., van Hilten, J.J., Bauer, M.C.R., Arbous, M.S., Marinus, J., Sarton, E.Y., \& Dahan, A. (2009). Ketamine produces effective and long-term pain relief in patients with complex regional pain syndrome type 1. Pain, 145, 304-311.

Snyder, A.W., Mulcahy, E., Taylor, J.L., Mitchell, D.J., Sachdev, P., \& Gandevia, S.C. (2003). Savant-like skills exposed in normal people by suppressing the left fronto-temporal lobe. Journal of Integrative Neuroscience, 2, 149-158.

Thut, G., Veniero, D., Romei, V., Miniussi, C., Schyns, P., \& Gross, J. (2011). Rhythmic TMS causes local entrainment of natural oscillatory signatures. Current Biology, 21, 1176-1185.

Walter, P. (2011). Transcranial electric stimulation (tES - tDCS; tRNS, tACS) methods. Neuropsychological Rehabilitation: An International Journal, 21, 602-617.

Wang, H-Y, Crupi, D., Liu, J., Stucky, A., Cruciata, G., Di Rocco, A., Friedman, E., Quartarone, A., Ghilardi, M.F. (2011). Repetitive transcranial magnetic stimulation enhances BDNF-TrkB signaling in both brain and lymphocyte. Journal of Neuroscience, 31, 11044-11054.

Warden, D., Rush, A.J., Trivedi, M.H., Fava, M., \& Wisniewski, S.R. (2007). The STAR*D project results: A comprehensive review of the findings. Current Psychiatry Reports, 9, 449-459.

Young, L., Camprodon, J.A., Hauser, M., Pascual-Leone, A., \& Saxe, R. (2010). Disruption of the right temporoparietal junction with transcranial magnetic stimulation reduces the role of beliefs in moral judgements. Proceedings of the National Academy of Sciences of the United States of America, 107, 6753-6758. 